\title{
Open aortic arch surgery: 10 years' single-center experience
}

\author{
Radosław Gocoł ${ }^{1}$, Jarosław Bis ${ }^{1,2}$, Damian Hudziak ${ }^{1}$, Magda Piekarska ${ }^{1,2}$, tukasz Morkisz ${ }^{1}$, Marek A. Deja ${ }^{1,2}$ \\ ${ }^{1}$ Department of Cardiac Surgery, Upper-Silesian Medical Center of the Medical University of Silesia, Katowice, \\ Poland \\ ${ }^{2}$ Department of Cardiac Surgery, Medical University of Silesia, School of Medicine, Katowice, Poland
}

Kardiochirurgia i Torakochirurgia Polska 2021; 18 (3): 159-164

\begin{abstract}
Introduction: Open aortic arch surgery is a complex cardiac surgical procedure.

Aim: We reviewed the 10-year outcomes of elective aortic arch aneurysm surgery in a single cardiac surgical center.

Material and methods: The analysis includes all patients who underwent elective aortic arch surgery at our institution between January 2010 and December 2020. The study population was divided into group A consisting of patients operated on during the first 5 years, and group B, including patients operated on during the subsequent 5 years. The groups were compared with regard to baseline characteristics, scope of the surgery, operative and postoperative data as well as morbidity and mortality.

Results: Eighty-six elective aortic arch procedures were performed during the analyzed period, including 25 (29\%) patients in group A and 61 (71\%) patients in group B. The hemiarch procedure was more frequently performed in group A (17 patients, $68 \%)$ in comparison to group B (21 patients, 34\%) ( $p=0.008)$. Stroke was recorded in $6(20 \%)$ patients from group $A$ and $5(8.2 \%)$ patients from group $\mathrm{B}(p=0.002)$. Five-year survival was $60 \pm 9.8 \%$ for group $\mathrm{A}$, and $81 \pm 6.2 \%$ for group $\mathrm{B}$ (log-rank test, $p=0.003$ ). Conclusions: After completion of the learning curve, open aortic arch surgery is associated with acceptable early mortality, low incidence of stroke, and a high 5-year survival rate.
\end{abstract}

Key words: aortic arch aneurysm, hemiarch replacement, total arch replacement.

\section{Introduction}

Open aortic arch surgery represents one of the most complex and demanding fields in modern adult cardiac surgery. Surgical treatment of isolated aortic arch aneurysms, or those co-existing with diseases of other segments of the aorta, is technically challenging, particularly when classical surgical techniques have to be supplemented with endovascular procedures. As aortic arch surgery requires temporary circulatory arrest, adequate protection of the central nervous system is of paramount importance to avoid complications associated with brain ischemia [1]. Several reports on the outcomes of open aortic arch surgery have been published in recent years. Most of them originate from large centers, with high patient output and multi-year experience in this field [2]. Nevertheless, data are scarce on whether open aortic arch surgery could be performed with reasonable outcomes in smaller, lower-volume centers.

\footnotetext{
Aim

In this study we reviewed the 10-year outcomes of elective open aortic arch surgery at our institution, and analyzed the impact of the surgeons' learning curve.
}

\section{Material and methods}

We performed a retrospective, observational study on patients who underwent elective aortic arch aneurysm surgery in the Department of Cardiac Surgery, Upper Silesian Medical Center of the Medical University of Silesia in the period from January 2010 until December 2020. Patients were referred for elective surgery according to current guidelines [3]. The following indications for aortic arch surgery were identified: aortic arch aneurysm, chronic aortic dissection, and saccular aneurysm of the aortic arch.

Patients with coexisting heart disease, requiring additional surgical procedures, were not excluded. However, patients with acute type $A$ aortic dissection undergoing emergency surgery were excluded.

The primary surgery outcome measure was mortality, ascertained from 1 or more of the following: patient's visit to the outpatient clinic, telephone contact with the patient or patient's relatives, National Registry of Cardiac Surgical Procedures (Krajowy Rejestr Operacji Kardiochirurgicznych) (www.krok.csioz.gov.pl). The Krajowy Rejestr Operacji Kardiochirurgicznych registry contains the mortality data obtained from the National Health Fund (Narodowy Fundusz Zdrowia). Death from all causes was included in the analy-

Address for correspondence: Radosław Gocoł MD, Department of Cardiac Surgery, Upper-Silesian Medical Center of the Medical University of Silesia, Katowice, Poland, e-mail: gocot@poczta.onet.pl

Received: 12.05.2021, accepted: 4.07.2021. 

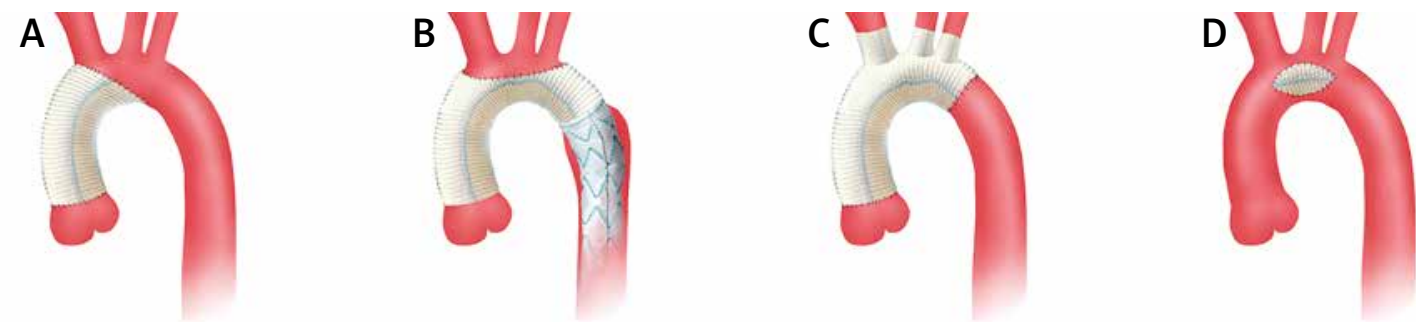

Figure 1. Open aortic arch surgery: A - hemiarch technique, B - total arch replacement with FET (Frozen Elephant Trunk, Evita Open System), C - total arch replacement, separate arch vessel anastomoses, D - Dacron patch

sis. To assess the impact of the surgical learning curve the study population was divided into group A consisting of patients operated on during the first 5 years, and group B, including patients operated on during the subsequent 5 years. The groups were compared with regard to baseline characteristics, scope of the surgery, operative and postoperative data as well as morbidity and mortality. The local Institutional Review Board opinion was requested. They decided that the follow-up was not a medical experiment, and therefore, their approval was not required (decision number KNW/0022/KB/284/17 dated 12 December 2017).

\section{Surgical technique}

Surgery was performed via median sternotomy or left lateral thoracotomy. The selection of one of the arterial accesses for cardiopulmonary bypass (CPB) (ascending aorta vs. aortic arch vs. brachiocephalic trunk vs right or left common carotid artery vs femoral artery) depended on the extent of aneurysm and/or dissection, the planned extent of the repair, as well as the cerebral protection method, and was left to the discretion of the operating surgeon. The right atrium was used for blood drainage for CPB. Depending on the central nervous system protection technique implemented during circulatory arrest, the patient was cooled to $17^{\circ} \mathrm{C}$ (deep hypothermic circulatory arrest - DHCA) or $26^{\circ} \mathrm{C}$ when selective brain perfusion was used. The patients' body temperature was measured simultaneously in the esophagus and in the bladder. One of the 3 types of cardioplegic regimens was used: cold del Nido cardioplegic solution, cold blood cardioplegic solution ( $4: 1$ ratio) and cold miniplegia.

One of the following techniques was used for central nervous system protection:

- deep hypothermic circulatory arrest (DHCA) [4],

- moderate hypothermia with circulatory arrest and selective antegrade cerebral perfusion (SACP) with monitoring of cerebral oxygenation (INVOS 5100C, Medtronic, Dublin, Ireland)) [5],

- in procedures involving the descending aorta, cerebrospinal fluid drainage with monitoring of cerebrospinal fluid pressure was performed [6].

The patients' arterial blood pressure was monitored in both left and right radial arteries and in one of the femoral arteries.

The scope of aortic arch procedures (open arch surgery): - partial replacement of the aortic arch (hemiarch) - involving replacement of the minor curvature of the aortic arch [7] (Figure $1 \mathrm{~A}$ ),
- total arch replacement (TAR) involving aortic arch replacement with concomitant re-implantation of arch vessels en-bloc or with separate anastomoses [8] (Figures 1 B, C), - implantation of a Dacron patch into the base of the saccular aneurysm (Figure 1 D).

Distal anastomosis with the descending aorta was performed end-to-end or in the case of a co-existing descending aorta aneurysm using the elephant trunk (ET) [9] or frozen elephant trunk (FET) technique [10]. The E-vita OPEN PLUS (Jotec Inc., Hechingen, Germany) system was used for the frozen elephant trunk procedures (Figure 1 B).

The additional procedures performed on the aorta included:

- supracoronary ascending aorta replacement for ascending aorta aneurysm,

- aortic root replacement with coronary artery re-implantation (Bentall de Bono technique) or valve sparing aortic root replacement (David method or Yacoub method) [11] for aortic root aneurysm.

Other concomitant procedures performed included: aortic valve replacement/aortic valve repair [12], mitral valve replacement/mitral valve repair, tricuspid valve repair, coronary artery bypass grafting.

\section{Statistical analysis}

Data are presented as mean (SD) when normally distributed or as median with $25^{\text {th }}$ and $75^{\text {th }}$ percentiles (interquartile range (IQR)) when normality assumptions (the Shapiro-Wilk test) were not met. Categorical data are expressed as a number and percentage. Kaplan-Meier time-to-event curves were generated for the entire cohort and the subgroups were compared with the log-rank (Mantel-Cox) test. The 5-year survival with standard error was estimated for both groups. GraphPad Prism 8.2.0 (GraphPad Software, San Diego, California, United States) was used for all statistical analysis, except the Cox analysis, which was done with IBM SPSS Statistics for Windows, version 22 (IBM Corp. Armonk, New York, United States).

\section{Results}

Eighty-six elective aortic arch procedures were performed during the analyzed period, including $25(29 \%)$ patients in group A and 61 (71\%) patients in group B. The indication for surgery was aortic arch aneurysm in 53 (61.5\%) patients, chronic aortic dissection in $30(35 \%)$ patients and saccular aneurysm in 3 (3.5\%) patients. Patients' median age (IQR) 
Table I. Demographic and baseline clinical characteristics of study patients

\begin{tabular}{|c|c|c|c|c|}
\hline Characteristics & $\begin{array}{c}\text { All } \\
(n=86)\end{array}$ & $\begin{array}{l}\text { Group A } \\
(n=25)\end{array}$ & $\begin{array}{l}\text { Group B } \\
(n=61)\end{array}$ & $P$-value \\
\hline Male sex & $50(58)$ & $17(68)$ & $33(54)$ & 0.34 \\
\hline Age [years], median (IQR) & $64(54-69)$ & $67(60-71)$ & $62(53-68)$ & 0.046 \\
\hline NYHA class: & & & & 0.049 \\
\hline NYHA I & $27(31)$ & $7(28)$ & $20(33)$ & \\
\hline NYHA II & $46(54)$ & $13(52)$ & $33(54)$ & \\
\hline NYHA III & $10(12)$ & $2(8.0)$ & $8(13)$ & \\
\hline NYHA IV & $3(3.5)$ & $3(12)$ & 0 & \\
\hline Previous cardiac surgery & $15(17)$ & $3(12)$ & $12(20)$ & 0.54 \\
\hline Chronic aortic dissection & $30(35)$ & $11(44)$ & $19(31)$ & 0.32 \\
\hline Aortic root aneurysm & $13(15)$ & $2(8.0)$ & $11(18)$ & 0.33 \\
\hline Ascending aorta aneurysm & $70(81)$ & $21(84)$ & $49(80)$ & 0.77 \\
\hline Descending aorta aneurysm & $33(38)$ & $6(24)$ & $27(44)$ & 0.09 \\
\hline Saccular aortic arch aneurysm & $3(3.5)$ & $2(8.0)$ & $1(1.6)$ & 0.20 \\
\hline Arterial hypertension & $65(78)$ & $20(90.9)$ & $45(74)$ & 0.13 \\
\hline Coronary artery disease & $18(21)$ & $6(24)$ & $12(20)$ & 0.77 \\
\hline Mitral valve regurgitation: & $(n=68)$ & $(n=7)$ & $(n=61)$ & 0.21 \\
\hline No & $12(18)$ & 0 & $12(20)$ & \\
\hline Trace & $26(38)$ & $5(71)$ & $21(34)$ & \\
\hline Mild & $19(28)$ & $1(14)$ & $18(30)$ & \\
\hline Moderate & $7(10)$ & 0 & $7(12)$ & \\
\hline Severe & $4(5.9)$ & $1(14)$ & $3(4.9)$ & \\
\hline Tricuspid valve regurgitation: & $(n=68)$ & $(n=7)$ & $(n=61)$ & 0.80 \\
\hline No & $22(32)$ & $2(29)$ & $20(33)$ & \\
\hline Trace & $19(28)$ & $3(43)$ & $16(26)$ & \\
\hline Mild & $19(28)$ & $1(14)$ & $18(30)$ & \\
\hline Moderate & $6(8.8)$ & $1(14)$ & $5(8.2)$ & \\
\hline Severe & $2(2.9)$ & 0 & $2(3.3)$ & \\
\hline Renal function: & & & & 0.13 \\
\hline Normal (GFR > $\left.85 \mathrm{ml} / \mathrm{min} / 1.73 \mathrm{~m}^{2}\right)$ & $50(58)$ & $12(48)$ & $38(62)$ & \\
\hline Moderately impaired (GFR $50-85$ ml/min/1.73 m²) & $28(33)$ & $8(32)$ & $20(33)$ & \\
\hline Severely impaired (GFR < $\left.35 \mathrm{ml} / \mathrm{min} / 1.73 \mathrm{~m}^{2}\right)$ & $7(8.1)$ & $4(16)$ & $3(4.9)$ & \\
\hline Dialysis & $1(1.2)$ & $1(4.0)$ & 0 & \\
\hline Diabetes $(n=83)$ & $9(11)$ & $\begin{array}{c}4(18) \\
(n=22)\end{array}$ & $\begin{array}{c}5(8.2) \\
(n=61)\end{array}$ & 0.24 \\
\hline BMI [kg/m²], median (IQR) & $27(24-30)$ & $28(25-30)$ & $26(24-30)$ & 0.25 \\
\hline Serum creatinine $[\mathrm{mg} / \mathrm{dl}]$, median (IQR) & $0.87(0.74-1.08)$ & $1.02(0.79-1.37)$ & $0.82(0.70-1.00)$ & 0.004 \\
\hline EF (\%), median (IQR) $(n=85)$ & $55(50-60)$ & $50(45-60)$ & $55(50-60)$ & 0.06 \\
\hline EUROSCORE II, median (IQR) & $4.98(3.01-8.89)$ & $4.29(2.82-8.39)$ & $5.34(3.23-9.15)$ & 0.42 \\
\hline
\end{tabular}

Data are presented as number (percentage) of patients unless otherwise indicated. BMI - body mass index, EF - ejection fraction, NYHA - New York Heart Association.

was 64 years (54-69); 50 (58\%) patients were male. Median (IQR) EuroSCORE II was 4.98 (3.01-8.89). Detailed baseline characteristics of the patients are presented in Table I.

The analysis of baseline characteristics in both study groups revealed that patients in group $B$ were significantly younger than those in group A, 62 years (53-68) vs. 67 years $(60-70)(p=0.046)$ and were in higher New York Heart Association (NYHA) classes $(p=0.049)$. Group B included more patients with co-existing descending aorta aneurysm, $27(44 \%)$ patients vs. $6(24 \%)$ patients $(p=0.09)$. Patients in group $A$ had significantly higher serum creatinine concentration (IQR) of $1.02 \mathrm{mg} / \mathrm{dl}(0.79-1.37)$ vs. $0.82 \mathrm{mg} / \mathrm{dl}(0.7-1.0)$ $(p=0.004)$, and lower left ventricular ejection fraction (LVEF) (IQR) of 50\% (45-60) vs. 55\% (50-60) $(p=0.06)$.

In the entire study population the hemiarch procedure was performed in 38 (44\%) patients and total aortic arch 
Table II. Surgery scope, data, complications

\begin{tabular}{|c|c|c|c|c|}
\hline Variable & $\begin{array}{c}\text { All } \\
(n=86)\end{array}$ & $\begin{array}{l}\text { Group A } \\
(n=25)\end{array}$ & $\begin{array}{l}\text { Group B } \\
(n=61)\end{array}$ & $P$-value \\
\hline Total aortic arch replacement: & $48(56)$ & $8(32)$ & $40(66)$ & 0.45 \\
\hline Island technique & $23(48)$ & $5(63)$ & $18(45)$ & \\
\hline Separate arch vessels anastomoses & $25(52)$ & $3(37)$ & $22(55)$ & \\
\hline Hemiarch replacement & $38(44)$ & $17(68)$ & $21(34)$ & 0.008 \\
\hline VSARR & $4(4.7)$ & 0 & $4(6.6)$ & 0.32 \\
\hline Bentall de Bono procedure & $3(3.5)$ & $2(8.0)$ & $1(1.6)$ & 0.20 \\
\hline Ascending aorta replacement & $70(81)$ & $21(84)$ & $49(80)$ & 0.77 \\
\hline Descending aorta replacement: & $33(38)$ & $6(24)$ & $27(44)$ & 0.09 \\
\hline FET & 25 (29) & $5(20)$ & 20 (33) & 0.30 \\
\hline AVR/AV repair: & $48(56)$ & $14(56)$ & $34(38)$ & 0.98 \\
\hline AV repair & & $7 / 14(50)$ & 27/34 (79) & 0.042 \\
\hline MVR/MV repair & $5(5.8)$ & $1(4.0)$ & $4(6.6)$ & 0.65 \\
\hline TV repair & $4(4.7)$ & 0 & $4(6.6)$ & 0.32 \\
\hline CABG & $19(22)$ & $5(20)$ & $14(23)$ & 0.99 \\
\hline Cannulation site: & & & & 0.07 \\
\hline Ascending aorta/arch & $9(10)$ & $5(20)$ & $4(6.6)$ & \\
\hline Brachiocephalic trunk & $56(65)$ & $10(40)$ & $46(75)$ & \\
\hline Left common carotid artery & $6(7.0)$ & $3(12)$ & $3(4.9)$ & \\
\hline Right common carotid artery & $7(8.1)$ & $3(12)$ & $4(6.6)$ & \\
\hline Femoral artery & $6(7.0)$ & $3(12)$ & $3(4.9)$ & \\
\hline CPB temperature $\left[{ }^{\circ} \mathrm{C}\right]$,median (IQR) & $26.75(26-28)$ & $28(26-28)$ & $26(26-28)$ & 0.65 \\
\hline SACP & $80(93)$ & $21(84)$ & $59(96.7)$ & 0.057 \\
\hline SACP time [min], median (IQR) & $35(21.25-54)$ & $35(20.5-41)$ & $35(22-55)$ & 0.56 \\
\hline DHCA & $8(9.3)$ & $6(24)$ & $2(3.3)$ & 0.007 \\
\hline DHCA time [min], median (IQR) & $21(15.5-27.25)$ & $18.5(12.25-25.75)$ & $31.0(22.0-40.0)$ & 0.18 \\
\hline X-clamp time [min], median (IQR) & $87(65-114)$ & $86(66-107)$ & $87(64-117)$ & 0.79 \\
\hline CPB time [min], median (IQR) & $190(139-232)$ & $163(125-208)$ & $200(148-254)$ & 0.03 \\
\hline Drainage [ml], median (IQR) & $780(560-1143)$ & $800(555-985)$ & $760(600-1190)$ & 0.63 \\
\hline Ventilation time $[\mathrm{h}]$, median (IQR) & $21.2(15.1-43.0)$ & $23.7(16.0-70.1)$ & $20.7(14.8-30.6)$ & 0.18 \\
\hline ICU stay [days], median (IQR) $(n=68)$ & $4(2-6)$ & $\begin{array}{l}6(3-6) \\
(n=7) \\
\end{array}$ & $4(2-6)$ & 0.36 \\
\hline Hospital stay [days], median (IQR) & $9(8-14.25)$ & $8(7-14.5)$ & $9(8-14.5)$ & 0.31 \\
\hline Early death & $10(11.6)$ & $5(20)$ & $5(8.2)$ & 0.15 \\
\hline Resternotomy for bleeding & $17(20)$ & $5(20)$ & $12(20)$ & 0.97 \\
\hline Stroke & $7(8.1)$ & $6(24)$ & 1(1.6) & 0.002 \\
\hline Renal failure/hemofiltration & $2(2.3)$ & $1(4.0 \%)$ & $1(1.6)$ & 0.50 \\
\hline Pneumonia & $7(8.1)$ & $3(12)$ & $4(6.6)$ & 0.41 \\
\hline Wound infection & $2(2.3)$ & 0 & $2(3.3)$ & 0.90 \\
\hline
\end{tabular}

Data are presented as number (percentage) of patients unless otherwise indicated. AV - aortic valve, AVR - aortic valve replacement, CABG - coronary artery bypass grafting, CPB - cardiopulmonary bypass, DHCA - deep hypothermic circulatory arrest, ICU - intensive care unit, IQR - interquartile range, MV - mitral valve, $\mathrm{MV}$ - mitral valve replacement, SACP - selective antegrade cerebral perfusion, TV - tricuspid valve, VSARR - valve sparing aortic root replacement.

replacement in $48(56 \%)$ patients. Detailed surgical data are presented in Table II.

The hemiarch procedure was more frequently performed in group $A$ (17 patients, 68\%) in comparison to group B (21 patients, 34\%) ( $p=0.008)$ (Figure 2). More procedures involving the descending aorta were performed in group B (27 patients, 44\%) than in group A (6 patients, 24\%) $(p=0.09)$, and $4(6.6 \%)$ patients in group B had an aortic valve sparing procedure in comparison to no patient in group A $(p=0.32)$. Deep hypothermia with circulatory arrest was more frequently used for brain protection in group $A$ : $6(24 \%)$ patients vs. $2(3.3 \%)$ patients $(p=0.007)$, whereas there were more selective brain perfusions in group B: 59 (96.7\%) patients vs. $21(84 \%)$ patients $(p=0.057)$. 


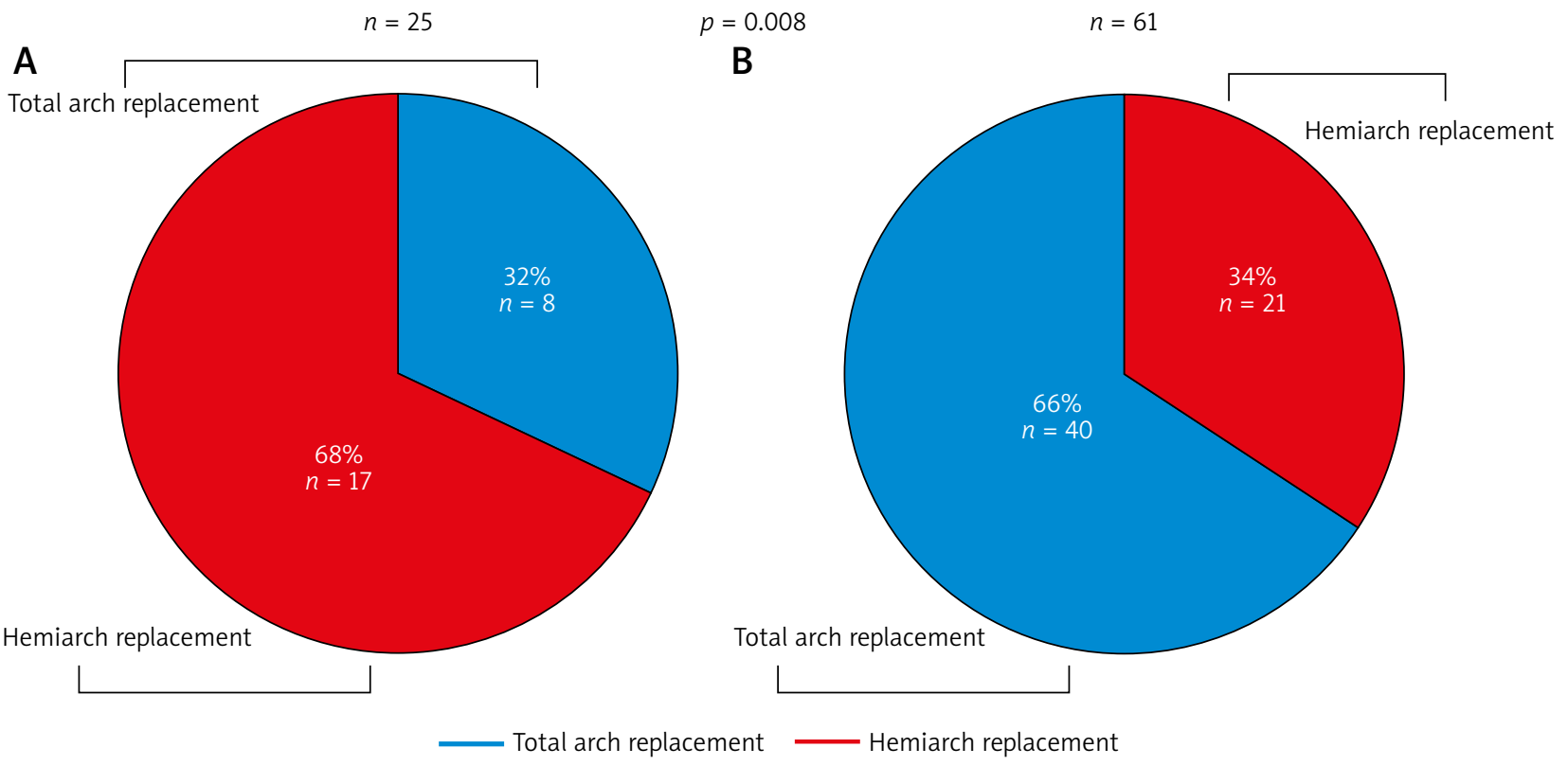

Figure 2. Comparison of hemiarch and total arch replacement in groups A (A) and B (B)

Significantly longer CPB time was recorded in group B (IQR): 200 minutes (148-254) vs. 163 minutes (125-208) $(p=0.03)$.

There were no differences between study groups regarding postoperative data such as bleeding volume, mechanical ventilation time and days of ICU and hospital stay.

The analysis of postoperative morbidity (Table II) revealed a significantly higher rate of stroke in group A: 6 (20\%) patients vs. $5(8.2 \%)$ patients $(p=0.002)$. There were no differences between groups with regard to the rate of chest reexploration due to bleeding, acute kidney failure, pneumonia and surgical wound infection.

This analysis includes complete data on mortality from all patients. The median (IQR) time of follow-up was 32.5 (13.9-56.6) months. Of note, there was higher early mortality (30 days post-surgery) in patients from group A: 5 (20\%) patients vs. $5(8.2 \%)$ patients ( $p=0.15)$.

Five-year survival estimated from Kaplan-Meier curve analysis was $60 \pm 9.8 \%$ for group $A$, and $81 \pm 6.2 \%$ for group B (Figure 3 ). The comparison of the study groups showed a significant difference in survival (log-rank test, $p=0.03)$ favoring those operated on during the second 5 -year period (group B).

\section{Discussion}

Open aortic arch surgery is a complex surgical procedure requiring meticulous planning and strict collaboration of surgical, anesthetic and perfusionist teams. Specifically, in this type of surgery temporary circulatory arrest is key to enable the replacement of the enlarged aortic segment. Consequently, during open aortic arch surgery, protection is required not only for the myocardium (as during standard classical cardiac surgery) but also for central nervous system and vital organs. Our analysis shows that patients undergoing aortic arch surgery are older (median: 64 years
(54-69)) with many co-existing conditions of the heart and the aorta, often implicating the expansion of the scope of planned surgery.

After having analyzed our 10-year outcomes of open aortic arch surgery, we were struck by the high early mortality of $11.6 \%$, significantly higher than the mortality of $5.5 \%$ reported in the literature to date [13]. Therefore, we decided to break up those 10 years into two 5-year periods.

The analysis of the first 5 years (group A) revealed that the early learning curve period is associated with outcomes significantly worse than those reported in the literature. Particularly noticeable are early mortality of $20 \%$ and the stroke rate of $24 \%$, whereas Thomas et al. [13] report rates of $5.5 \%$ and $5 \%$ respectively after elective surgery. These results can be regarded as even poorer, keeping in mind that in most cases (68\%) the surgery of the aortic arch was limited to only partial replacement (hemiarch). In this

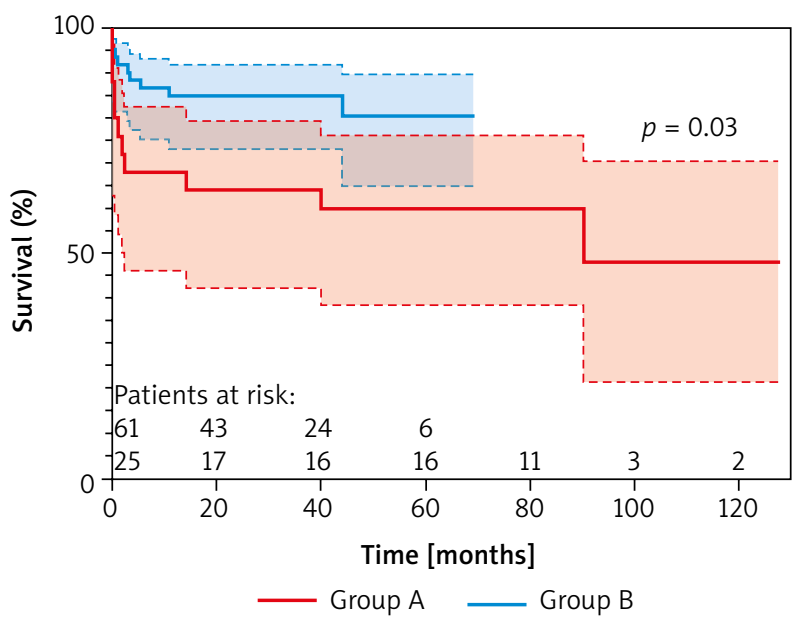

Figure 3. Kaplan-Meier survival curves with $95 \% \mathrm{Cl}$. The subgroups were compared with the log-rank (Mantel-Cox) test 
type of approach Lima et al. [14] report early mortality of $2.9 \%$ and a stroke rate of $4.1 \%$. Worse surgical outcomes in group A are reflected by longer ICU stay, longer time of mechanical ventilation and more acute kidney failure and pneumonia in comparison to group B. Another important factor affecting the postoperative outcome was the central nervous system protection, which in as many as $24 \%$ of patients was limited to deep hypothermic circulatory arrest. This translated into a high rate of stroke (24\%).

With experience gained the number of operated patients increased from 25 (29\%) patients in group A to 61 (71\%) patients in group $B$, and the scope of procedures became more extended (from 32\% total arch replacements in group A to $66 \%$ in group B). Additionally, the descending aorta and aortic root became more frequently addressed. Frozen elephant trunk with the use of the E-vita OPEN PLUS system (Jotec, Hechingen, Germany) became the preferred technique for procedures involving the descending aorta.

In the second study group, complementary surgical procedures on the aortic root (valve sparing aortic root replacement (VSARR)) and aortic valve, even though technically demanding and time consuming, were not avoided. Of note is the rising rate of repaired aortic valves from $50 \%$ in group A to $79 \%$ in group B. The extending scope of surgery resulted in longer CPB time in group B: 200 minutes vs. 163 minutes $(p=0.003)$.

Despite the fact that patients in group B underwent more complex aortic arch surgery, had more additional coronary and valvular procedures, and more redo procedures, the outcomes were significantly better than in group A. The early mortality of $8.2 \%$ is similar to the data reported by Patel et al. [15] in their large series of 721 patients, and even better than the early mortality of $15 \%$ reported from another Polish center by Hirnle et al. [16].

Meticulous central nervous system protection contributed to the reduction of the stroke rate to $1.6 \%$, which is an excellent result, better than the rates reported by Patel et al. [15] (4.8\%) and Hirnle et al. [16] (9\%). This low frequency of stroke is related to the implementation of selective brain perfusion with cerebral oxygenation monitoring in the majority of operated patients (96.7\%), whereas DHCA was used in only 2 (3.3\%) patients.

\section{Conclusions}

It seems that the key factor impacting the outcomes of open aortic arch surgery is the experience of the team, which translates into reproducible results on par with those reported by other surgical teams specializing in surgery of the aortic arch. Estimated 5-year survival of $81 \%$ after open aortic arch surgery makes it a reliable and reproducible cardiac surgical procedure, associated with good long-term outcomes.

After completion of the learning curve, open aortic arch surgery is associated with acceptable early mortality, low morbidity (low stroke rate in particular), and good longterm survival.

\section{Disclosure}

The authors report no conflict of interest.

\section{References}

1. Tian DH, Wan B, Bannon PG, Misfeld M, LeMaire SA, Kazui T, Kouchoukos NT, Elefteriades JA, Bavaria JE, Coselli JS, Griepp RB, Mohr FW, Oo A, Svensson LG, Hughes GC. Underwood MJ, Chen EP, Sundt TM, Yan TD. A meta-analysis of deep hypothermic circulatory arrest alone versus with adjunctive selective antegrade cerebral perfusion. Ann Cardiothorac Surg 2013; 2: 261-270.

2. Cefarelli M, Murana G, Surace GG, Castrovinci S, Jafrancesco G, Kelder JC, Klein P, Sonker U, Morshuis WJ, Heijmen RH. Elective aortic arch repair: factors influencing neurologic outcome in 791 patients. Ann Thorac Surg 2017; 104: 2016-2023.

3. Erbel R, Aboyans V, Boileau C, Bossone E, Di Bartolomeo R, Eggebrecht $H$, Evangelista A, Falk V, Frank H, Gaemperli O, Grabenwöger M, Haverich A, lung B, Manolis AJ, Meijboom F, Nienaber CA, Roffi M, Rousseau H, Sechtem U, Sirnes PA, von Allmen RS, Vrints CJM, ESC Committee for Practice Guidelines. 2014 ESC Guidelines on the diagnosis and treatment of aortic diseases: document covering acute and chronic aortic diseases of the thoracic and abdominal aorta of the adult. The Task Force for the Diagnosis and Treatment of Aortic Diseases of the European Society of Cardiology (ESC). Eur Heart J 2014; 35: 2873-2926.

4. Ziganshin BA, Elefteriades JA. Deep hypothermic circulatory arrest. Ann Cardiothorac Surg 2013; 2: 303-315.

5. Leshnower BG, Myung RJ, Kilgo PD, Vassiliades TA, Vega JD, Thourani VH, Puskas JD, Guyton RA, Chen EP. Moderate hypothermia and unilateral selective antegrade cerebral perfusion: a contemporary cerebral protection strategy for aortic arch surgery. Ann Thorac Surg 2010; 90: 547-554.

6. Wortmann M, Böckler D, Geisbüsch P. Perioperative cerebrospinal fluid drainage for the prevention of spinal ischemia after endovascular aortic repair. Gefasschirurgie 2017; 22: 35-40.

7. MacGillivray TE. How I teach hemi-arch replacement. Ann Thorac Surg 2016; 101: 1251-1254.

8. Minatoya K, Inoue Y, Sasaki H, Tanaka H, Seike Y, Oda T, Omura A, Iba Y, Ogino $\mathrm{H}$, Kobayashi J. Total arch replacement using a 4-branched graft with antegrade cerebral perfusion. J Thorac Cardiovasc Surg 2019; 157: 1370-1378.

9. Strauch JT, Spielvogel D, Lauten A, Galla JD, Lansman SL, McMurtry K, Griepp RB. Technical advances in total aortic arch replacement. Ann Thorac Surg 2004; 77: 581-589.

10. Di Bartolomeo R, Pellicciari G, Cefarelli M, Eusanio MD. Frozen elephant trunk surgery using the E-vita open plus prosthesis. Ann Cardiothorac Surg 2013; 2: 656-659.

11. Gocoł R, Malinowski M, Bis J, Hudziak D, Morkisz $Ł$, Elżbieciak M, Wojakowski W, Deja MA. Aneurysm of the aortic root and valve-sparing aortic root replacement: long-term outcomes from a single Polish center. Kardiol Pol 2020; 78: 1235-1242.

12. Gocoł R, Malinowski M, Bis J, Hudziak D, Ciosek J, Wojakowski W, GaszewskaŻurek E, Jasiński M, Deja MA. Long-term outcomes of aortic valve repair in over 500 consecutive patients: a single-center experience. Kardiol Pol 2020; 78: 861-868.

13. Thomas M, Li Z, Cook DJ, Greason KL, Sundt TM. Contemporary results of open aortic arch surgery. J Thorac Cardiovasc Surg 2012; 144: 838-844.

14. Lima B, Williams JB, Bhattacharya SD, Shah AA, Andersen N, Gaca JG, Hughes GC. Results of proximal arch replacement using deep hypothermia for circulatory arrest: is moderate hypothermia really justifiable? Am Surg 2011; 77: 1438-1444.

15. Patel HJ, Nguyen C, Diener AC, Passow MC, Salata D, Deeb GM. Open arch reconstruction in the endovascular era: analysis of 721 patients over 17 years. J Thorac Cardiovasc Surg 2011; 141: 1417-1423.

16. Hirnle T, Stankiewicz A, Matlak K, Frank M, Trzciński R, Lejko A, Niedźwiecki A, Mitrosz M, Dmitruk I, Milewska-Buzun M, Hirnle G. Single-centre experience in surgery of acute aortic type A dissection and true aortic arch aneurysm. Kardiol Pol 2016; 74: 994-1001. 